\title{
Prepare to be Offended Everywhere: How Cultural Safety In Public Places Can Prevent Violent Attacks
}

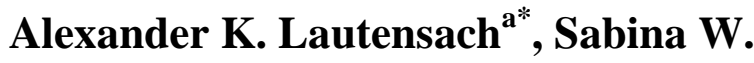 \\ Lautensach $^{\text {b }}$
}

${ }^{a}$ University of Northern British Columbia, 4837 Keith Avenue, Terrace, B.C. Canada

${ }^{b}$ Human Security Institute (Canada), 1025 Farkvam Road, Terrace, B.C. Canada

Received: January 12, 2015/ Accepted: May 11, 2015

\begin{abstract}
The greater mobility of people and the worldwide displacement of millions, forced or voluntary, has directed attention to their human security in foreign environments. We propose that a focus on cultural safety is becoming an essential requirement for the human security of displaced minorities everywhere, building on previous work in educational settings [6]. As a necessary though insufficient condition for human security, cultural safety is affected by dependency relationships, power imbalances, dominant paradigms, and norms of public conduct as they apply to displaced cultural minorities. The central question how cultural safety could be enhanced is addressed through empirical scenarios where the cultural safety of individuals was placed in jeopardy. Such events often manifest as the perception of offence, sometimes leading to violent conflict. Recognizing the futility of attempts to prevent all and any offence, our arguments amount to a novel approach to strengthen cultural safety, and thus human security: preparing both sides for offensive experiences as a means to pre-empt counterproductive reactions. We discuss strategies toward that goal that might allow individuals, families, larger groups and organizations to work collaboratively towards ensuring the cultural safety of displaced people, thus making a vital contribution towards sustainable human security.
\end{abstract}

Keywords: Cultural safety; displaced people; conflict prevention.

\section{Introduction}

The January 2015 terror attacks against the Charlie Hebdo office in Paris illustrated once again the inherent limitations in the armamentarium of counterterrorism - essentially reactive and resource intensive, with poor predictive and preventive capabilities apart from occasional pre-emptive strikes, and entirely unsustainable from a cost-benefit perspective, both in terms of

\footnotetext{
Corresponding Author
}

Tel.: +1 250615 3334; Fax.: +1 250615 5478; E-mail: alexl@unbc.ca economic and humanitarian costs. Only four days after the initial attack another one occurred at a German publisher's. To become sustainable and more capable of eventual success, efforts against terrorism must turn to new preventive approaches that focus on intercultural offence. This essay outlines one such approach that relies on the concept of cultural safety.

At the other end of the scale of violence, in the 2014 tourist season a novel phenomenon emerged in the media: 'flight rage', akin to road rage, manifesting as violent disputes between passengers and officials over reclining airplane seats, noise disturbance, security hassles and procedural delays. Flight rage caused delays or interruptions of flights to dispose of passengers deemed a security hazard. The phenomenon illustrates the mounting psychological pressures experienced by passengers in a climate of political paranoia, booming security and intelligence industries, and genuine concerns over international grievances and new health threats. Flight rage also represents an example of inadvertent misbehaviour to which offence is taken as a result of a misinterpretation of culturally contingent behavioural cues; the offence often gives rise to verbal abuse and physical violence. This paper suggests how such reactions to offence might be prevented.

In its effort to survive in a rapidly changing planetary environment, our growing population will encounter new security challenges while existing ones will intensify. Extreme weather events and other environmental catastrophes will compromise the security of increasing portions of humanity. The distinctions between traditional security problems such as armed conflicts, socio-political problems of poverty and injustice, and environmental problems such as famines and displacements have become blurred. In response to that amalgamation of sources of insecurity, many analysts have favoured comprehensive models of human security. Their descriptive and predictive power comes from their transdisciplinarity and their attention to the well-being of individuals and communities [1, 2].

We focus on the particular human security concerns that arise from the situation of displaced ethnocultural minorities, such as Muslims in Europe. Here, too, a well-known source of conflict increases in both frequency and severity. While displaced people have encountered challenging new cultural environments throughout history, the frequency and ramifications of such encounters are increasing. As well, the reasons for displacement armed conflict, political persecution, climate disruption, resource shortages, regional population pressure - are multiplying as the conditions for our survival are changing globally [3:57]. In 2014, the number of refugees from Syria alone exceeded three million [4]. Moreover, those encounters are making bigger waves as globalisation enhances people's mobility, by increasing the number of voices and by increasing the reach of each voice.

Modernist discourse idealises technological development in communication and transportation as the roadway towards the establishment of a global community of empowered rational actors [5]. Yet in spite of our increased connectedness humanity does not seem to amalgamate easily; we tend to insist on keeping our different worldviews, spiritual beliefs and cultural idiosyncrasies. The upshot is that most of us are more frequently confronted with expressions and manifestations of difference. This gives rise to cross-cultural conflict - "actions taken by someone, or reactions to the protest of someone, who felt offended in their deeply felt beliefs and values by somebody else's actions" [6:183]. People easily take offence when someone blatantly expresses herself in front of them in language or behaviour that violate their own deeply held values. The offence becomes particularly deep if the offended individual feels bereft of means for recourse as a result of some 
form of disempowerment, exemplified by the frustration experienced by today's economy air passenger confronted with a seat that refuses to recline, blocked by a fellow passenger who insists on retaining valuable leg room as part of their individual sphere of autonomy.

Obviously, in the absence of unusually forgiving tolerance this kind of conflict easily turns violent. Beyond the relatively trivial example of flight rage, the violence can become massive and widespread if the offence is experienced collectively, if it involves values that are held not just personally but by entire ethnocultural groups. In an earlier work we explored the opportunities for mitigating and preventing such conflict in formal education through proactive and preventive strategies [6]. The guiding concept for devising such strategies is cultural safety and how preparing people for offensive encounters can enhance it by empowering them to control their reactions reflectively before feeling compelled to join violent groups. In this paper we take a wider view to identify which strategies might prove helpful for 'preparing to be offended' in the public domain.

The assumption underlying such strategies is that the offensive experience in principle is inevitable. As long as the offensive behaviour is inadvertent the offence is accidental and entirely in the eyes of the beholder. Even satirical cartoons are not generally produced for the main purpose of giving offence but rather for inciting critical thinking and discussion. This lack of intent places much of the onus for preventive measures on the side of the beholder or recipient, although it by no means frees the potential offender from an obligation to engage in reflective and proactive analysis of their own conduct. As our title suggests, we shall concentrate on the recipient side. As the passive party in the encounter in whose perception the offence might take place, the recipient is better able to examine the criteria under which a particular behaviour constitutes an offence for him/her, and to analyse his/her reaction to that experience. We note that in the case of displaced people it is not necessarily the host culture that ends up on the recipient's side; it is equally conceivable that the newcomer feels offended by the behaviour of the host, as the attacks on Charlie Hebdo illustrate. Yet the power differential lends advantage to the host, which arguably adds to his moral obligation to prevent conflict. We shall discuss questions about moral obligations in section 4; first, we explain how we place cultural safety within the wider concept of human security.

\section{Cultural Safety as Situated Within Human Security}

We defined cultural safety in professional situations as "a condition perceived by vulnerable recipients ... that inspires them with the confidence that no psychological harm will come to them in their dependent situation. It includes all the provisions and considerations contributed by the practitioner in meeting that requirement but it is defined by the beholder" [6:185]. Conversely, "unsafe cultural practice is any action that diminishes, demeans or disempowers the cultural identity and well being of an individual" or group [7:3]. Thus the conceptual basis of cultural safety lies primarily in the ethical theories of justice and non-maleficence. A lack of cultural safety entails the risks of shame and physical harm. Cultural safety is promoted by the effective treatment of a person from another culture by someone who has undertaken a process of reflection on his/her own cultural identity and recognizes the impact of his/her culture on his/her behaviour [8:7]. Cultural safety is often jeopardised in situations where two parties are separated by a power differential caused by inequities in capital, influence, knowledge, resources, or social status.

While there have been no theoretically grounded attempts to conceptually integrate cultural safety into the wider human security discourse we believe that both fields would benefit from explicating the connections between them. Like cultural safety, human security is a subjective condition defined in the eyes of the beholder. Both arise from a primary concern with justice and human rights, manifested as the 'freedom from fear' and 'freedom to live in dignity' dictums in the UN's human security publications [9]. They share a focus on personal insecurity: With both concepts it is possible to identify universal and particular sources of threats, to define conditions most likely to be experienced as unsafe and to describe determinants that promote the opposite [8]. Thus they truly qualify as perspectives of "security from below" - subjectively defined and culturally embedded [11].

Under the Four Pillar Model [12], human security is determined by four areas that traditionally were considered the domains of diverse academic disciplines: the military-strategic security of the state and its citizenry; economic security, particularly its conceptualization through steady-state models of sustainable economies; the health of populations as described by epidemiology and community health; and environmental security, primarily determined by the complex interactions between human populations and the source and sink functions of their host ecosystems. The four pillars include diverse sources of threats, equivalent to the 'seven dimensions' of human security outlined in the 1994 Human Development Report [13]: economic, food, health, environmental, personal, community, and political security.

An important strength of those conceptions of human security is their transdisciplinarity - their comprehensive coverage of interdependent sources of insecurity that were traditionally considered under the purview of different academic specialties. The transdisciplinary approach is versatile and capable of characterizing synergistic effects and multifactorial causation among diverse sources of insecurity [14]. While older descriptive models resting on lists of pillars or dimensions paid scant attention to interactions and hierarchies, more recent conceptual models of human security [15], such as the "concentric circle model' [16], have addressed that shortcoming. With the help of that transdisciplinary approach shared by most theories of human security the determinants of cultural safety can be identified as human security determinants: psychological well-being, personal autonomy, human dignity, and freedom from fear. Having established the commensurability of the two concepts, we can integrate cultural safety into the conceptual framework of human security.

Bringing the two concepts of cultural safety and human security together, we note that cultural safety strengthens what Eckersley [17:196] called the "primary political virtue of human security: it unsettles and questions conventional understandings of security". We suggest that cultural safety acts within human security as a necessary but insufficient condition. We base this suggestion on two considerations. First, cultural safety prevents tensions and conflicts between ethnocultural groups by providing vulnerable individuals and groups with the confidence that no harm will come to them from the other side. Secondly, in the absence of sufficient cultural safety such tensions tend to escalate through multiple rounds of misunderstandings and defensive reactions on both sides, often giving rise to violence. Thus, cultural safety functions as a sine qua non condition primarily for sociopolitical human security. Its absence gives rise to organised crime, random violence, exploitation, poor health, violent confinement, and terrorism. Cultural safety becomes vitally important in situations where deep intercultural differences create a significant gap in political identities and where large numbers of individuals experience that gap in ways that affect the quality of their lives. In the next section we shall argue that it is the situation of displaced 
populations within their host societies where this dependence manifests most frequently and with the most critical ramifications.

\section{Displaced People Lack Cultural Safety}

Throughout history individuals and populations found themselves under pressure to leave their traditional homelands to seek out better futures elsewhere, driven by economic hardship, political conflict, cultural persecution, environmental disasters and resource scarcity. Displacement can be voluntary or forced, individual or collective, organised or chaotic. In recent centuries it became increasingly likely that the destination region was already inhabited, which created potential friction between newcomers and hosts. Frictions are particularly likely in cases of a large intercultural gap in values, worldviews, religions or traditional life styles. Other vulnerability factors include the past history of relations between the two parties, the extent of the power differential between them, the visibility of differences, the dominant paradigms and attitudes informing their behaviour, and traditional norms of public conduct.

Those vulnerability factors operate in principle with any tourist, visitor, migrant worker or immigrant. They loom particularly large in the case of refugees, persons who were displaced against their will to the effect that precludes their return to their homeland under pain of physical harm. This definition includes environmental refugees, in contrast to the definition in the United Nations' 1951 Convention Relating to the Status of Refugees and the 1967 Protocol [18:118] which vastly underestimates refugee numbers [19]. Refugees are more vulnerable because their lives are characterised by a paucity of choices and general economic poverty, by a dependency on anonymous and seemingly omnipotent bureaucracies, by a lack of familiarity with the host society's norms, traditions and often language, and consequently by their special susceptibility to exploitation and violence [20, 3:59-61].

The vulnerability of ethnoculturally identifiable newcomers also depends on the degree to which their presence is seen as a threat to the traditional ways of life of the host culture. The extent of such a perceived threat determines the likelihood of deliberate xenophobic affronts, as opposed to offence occurring inadvertently. The extent to which the Other is perceived as a threat is affected by a culture's degree of parochialism, the degree to which it disregards or devalues exogenous influences that clash with local views. Cultural parochialism, sometimes referred to as 'intolerance for ambiguity' [21], manifests as a lack of interest in other cultures and places, automatic preference for the familiar over the unfamiliar, distrust of strangers and their ways, and fear of the unknown.

Without intense and widely shared cultural parochialism, the human security of thousands of ethnic Japanese in North America could not have been violated by their forced internment during WWII. The example shows not only the significance of parochialism as a determinant of insecurity but it also points to what kind of human security is mainly supported by cultural safety - the security of individuals' human rights as well as the collective security of identifiable ethnocultural minorities, in this case from legally sanctioned abuse empowered by immoral consensus. Only a strong, well informed and morally reflective civil society can stand up to governmental violence in such cases.

For the reasons stated in the introduction, our observations have focused primarily on the cultural safety cum human security of migrants in their host countries. Yet, as the Charlie Hebdo attack exemplified, significant threats can also arise to host societies from the presence of culturally unsafe migrant minorities. Particularly pertinent to this essay is the observation that those threats tend to be amplified by the lack of cultural safety among those migrants [3:61-63].

The continued growth of human populations and their activities has resulted in an exponential increase in their ecological impact on the biosphere, leading since the 1980 os to ecological overshoot [22] - the situation where the collective impact exceeds the capacity of the biosphere to sustainably support it. Overshoot was first demonstrated by comparisons of ecological footprints against biocapacities $[23,24]$ and later by analyses that showed the transgression of specific environmental boundaries [25]. The growing impacts, as well as the self-reinforcing effects of overshoot have contributed to the proliferation of violent conflict $[26,27]$ and resource shortages [28] that have caused a massive increase in the numbers of displaced people worldwide. In 2013, unprecedented numbers of newly displaced peoples (10.7 million) swelled the total of forcibly displaced peoples to 51.2 million [4], not counting environmental refugees. Desertification alone affects 250 million people, and about two billion are at risk [29]; it affects $23 \%$ of all land presently under cultivation [30]. The UN projects total numbers of migrants to increase from 232 million in 2013 to between 415 and 513 million by 2050 [31]. Those populations will severely affect the human security of prospective host countries [32] and threaten to render existing security regimes unsustainable.

A recent report by UNHCR [4] lists as the top countries of origin Afghanistan, Syria and Somalia; top host countries are Pakistan, Iran, Lebanon, Jordan and Turkey. While the crises at points of origin show no signs of abating, the limited capacities of those hosts will soon require that migrations be diverted elsewhere. Host societies further afield will be largely non-Muslim and culturally more alien to those refugees, which will further increase the incidence of intercultural conflicts. Those trends render more severe the sources of insecurity outlined above, and they pose particular challenges to the sustainability of human security. They lend additional urgency to the need for addressing the determinants of intercultural conflict. Those trends are also shifting the balance towards genuine refugees who do not have the option of returning to their land of origin.

Two less harmful trends that have contributed to the increased incidence of intercultural contact are the aforementioned expansion of communications among people over great distances and their increased mobility as an indicator of 'globalisation' [33], causing the rise in the number of foreign students at Western universities [34], the brain drain of academic elites from developing countries, and the astounding growth in global tourism. To summarise, those factors contributing to displacement result from massive global environmental and socio-political changes that themselves can no longer be reversed or mitigated. They underscore the urgency and the expediency of strategic efforts towards enhancing the cultural safety of vulnerable populations.

\section{Enhancing the Safety of the Culturally Different}

\subsection{The Need for Intervention in the Public Sphere}

The situation of international students illustrates both the importance of the educational sector as a forum for intercultural contact and the effect of the power differential on cultural safety. A case that made headlines in Canada involved a Muslim male student who complained about being forced to take tutorials together with female students, claiming that it violated his religious rights. The professor in charge refused to give in to the student's demand for separate instruction, whereupon he was disciplined by the university administration [35]. The case elicited 
debate about the extent to which the Canadian ideal of multiculturalism should inform the accommodation of preferences that are perceived to violate ideals of pluralism and tolerance also phrased as the problem of tolerating intolerance. Other important questions focused on the moral rights and obligations of newcomers versus those of the host culture. Eventually public pressure led to the professor's exoneration while the questions remained largely unresolved.

This example reinforces our proposition that attention to cultural safety is important in education and health care [6]. Yet our preceding discussion indicates that the need for cultural safety transcends the realm of the service professions and hints at a much greater significance in contexts that involve the wider public sphere and particularly displaced people. Whereas health care and education deal primarily with individuals, cultural safety issues in the public sphere involve larger numbers of people. Chronic negligence of cultural safety can lead to horrific abuses of human rights. Some disaffected individuals will respond by committing suicide and/or acts of terrorism as in the Charlie Hebdo case, precipitating large-scale police action or military retaliation that can even grow into protracted wars.

Cultural safety in the public domain can do much more than prevent terrorism. Its importance is illustrated by the case of Ruzwana Bashir [36], an abuse victim of British-Pakistani origin who went public when an organised network of child abusers was uncovered around the UK town of Rotherham. An official report confirmed systematic abuse within the Pakistani expatriate community of at least 1,400 children over at least sixteen years, which authorities refused to report or investigate [37]. In a typical twist of culturally contingent views of justice, after repeated attempts to convince Ms Bashir to remain quiet, her own family ostracised her for 'bringing shame onto the family'. Likewise, on his return from an eight-year prison sentence a perpetrator was accepted back into the community without much acknowledgement of his wrongdoings. The Rotherham network gained infamy from its sheer volume but it is by no means an isolated case. The pervasive occurrence of 'honour killings' and other physical assaults on abused girls in Western countries with sizeable Asian and Middle Eastern immigrant populations shows that the problem for human security is serious and widespread. The result is physical violence against disempowered members of a cultural minority, often perpetrated by their own families as a reaction to a perceived offence.

The legal systems of the host countries and their express commitments to uphold basic human rights and dignity within their borders oblige authorities and immigrant communities to address these problems. An overhaul of police, schools and social services might hamper future attempts by the authorities to turn a blind eye. Bashir [36] suggested four specific strategies and areas of reform: better communication of frontline personnel with victims, especially young girls; mandatory reporting of potential sexual abuse; improved support for victims and streamlining of prosecutions; and key community appointees responsible for ensuring that the policies are implemented. But a sustained and comprehensive change requires the cooperation of the wider public. In the remaining part of this section we shall argue that as an additional strategy, education of the public can make a powerful contribution, specifically geared towards the precautionary and anticipatory preparation for offence.

\subsection{Educating the Public for Cultural Safety: Ends and Means}

From a humanist perspective, a satisfactory response to such violations of human rights and dignity should be preventive rather than punitive, and it must involve both sides to yield sustainable benefits. It is a tall order to demand of any culture to start questioning its own taboos. In a minority culture such questioning is discouraged as long as its adherents perceive themselves on the defensive against 'corrupting' external influences - in other words, they perceive their group as culturally unsafe. This defensive view also relies on the misconception that one's culture can be protected from any and all change. Yet such conservatism can also help to preserve cultural diversity and facilitate the survival of indigenous cultures and languages threatened by post-colonial assimilation. The challenge is to accept the overarching priority of ensuring the cultural safety of all affected individuals and to exercise good judgment in targeting only those practices that could compromise it. A promising place to begin might be at the heart of the taboo against admitting victimisation, namely the perception of offence.

According to Ramsden's [38] educational model, cultural safety develops in four successive stages, beginning with cultural awareness based on a cognitive understanding of information about cultural differences and the resulting challenges. The second stage consists of the development of cultural sensitivity and relies mostly on changes in attitudes and values, towards a willingness to learn about each other, and towards mutual respect and trust. It is from this stage onward that the perception of offence can be addressed. In the third stage learners develop cultural competencies such as skills for intercultural communication, leadership, reflective conflict resolution, negotiating differences, and establishing a culture of tolerance and fairness. In the fourth stage those competencies are brought to bear on the social environment to bring about cultural safety for all parties.

Although the victimisation of women such as Ms Bashir seems to occur mostly within their culture, Ramsden's four-stage intercultural model can be used to address it, for several reasons. Firstly, the issue involves two cultures, not one. The objections rely on the legal and moral framework of a Western-style host society to which all immigrants are obliged to subscribe. Secondly, the model encourages the development of cultural safety as a personal goal and its elevation to a moral norm, which can motivate a person to question traditional taboos and perceptions of offence. Thirdly, the development of reflective skills in stage three, the ability to step outside of oneself and assess one's potential reactions and their implications, can greatly empower such questioning. The potential benefits of those steps justify informal educational efforts in whatever form seems feasible as another promising strategy towards cultural safety and thus human security.

The overarching goal of all efforts, educational and otherwise, is utilitarian: to recognise cultural safety as a positive human right and to maximise it for all parties. Ramsden's [38] stage model provides a broad picture of educational outcomes. In the public context, everyone potentially affects everyone else's cultural safety. How the individual thinks and behaves under those conditions is determined by his/her cultural competence. Rights and duties are more evenly distributed, although they differ for host and newcomer. They will differ in the case of newcomers who arrived voluntarily, but the differences are more severe for genuine refugees and other involuntary migrants. Likewise, the range of available options depends on who does the offending - a faceless corporation or government, or a person sitting in the next bus seat. The extent of the power differential also affects the recipient's range of options. The preparation for feeling offended includes developing cultural sensitivity for the Other on both sides and of cultural competence to assess the situation.

Besides preparing to feel offended, educational objectives should include rendering explicit the conditions under which people feel culturally unsafe, discussing the power differential and other vulnerability factors as discussed above, bridging between generations of immigrants and social classes, and by exploring the limits of one's 'tolerance' and how they are determined. 
Establishing a consensus on what constitutes human dignity complementing the widespread discourse based on rights - and how it might be protected from violations in the form of instrumentalisation and humiliation of persons [39] is another important objective.

Clearly, educational endeavours amount to more than a mere build-up in mutual tolerance; gross violations of universal human rights and dignity cannot be excused on cultural grounds - a realisation that in itself constitutes a learning objective. The challenge is to decide where to draw the line and to formulate a code of cultural pluralism demanding that "we need fully to understand and appreciate the viewpoint of a particular standard before we judge it as inadequate" [40:32]. This amounts to a carefully deliberated balance between cultural relativism (expressed as moral pluralism in the multicultural ideal) and moral universalism (as exemplified by the Universal Declaration of Human Rights) [41]. 'Political correctness' tends to suppress such deliberations [42].

While the ends of education for cultural safety can thus be defined and prescribed quite clearly, the means are fraught with uncertainty, beginning with the question of ownership. Who should be tasked with convincing common citizens that it is in their interest to question power differentials and their own cultural norms, to come to the realisation that perhaps their country is in fact not the greatest in the world in every respect? There is no professional support network in the public sphere, no occasion for formal education except in employee training and in the briefing of immigration applicants, and possibly through the influence of religious leaders. Otherwise, much of the educational duty falls to the media and entertainment industries, which at a time of their privatisation under neo-liberal fundamentalism present a challenge of its own. Likewise, social media seem to offer as many pitfalls as opportunities in this regard. Those potential agents can be encouraged and incentivised to participate in the educational efforts but compulsion is ruled out in the liberal democracies of the West. And yet, the public in those countries does on occasion learn through broadly organised educational initiatives, as shown in the changes of general views towards impaired driving and smoking in public places. While it often falls on governments to initiate and support such campaigns, civil society, through its informal channels and means, can accomplishes much in terms of public education and human security [43]. In this conclusion we side with those who regard human security primarily as a bottom-up project, and only secondarily as a matter between governments [11].

To summarise, while the ends of education in the public domain can be readily derived and formulated from conceptual models, in this case the developmental model of cultural safety, the means of such education are heterogeneous and depend on the context. Nevertheless, the potential benefits as well as the consequences of inaction, render the effort imperative. We have argued that the key concept of preparing to be offended carries great educational potential for its simplicity and conciseness. Still, considering its limited potential in the public sphere, education must be complemented by other political efforts, exemplified by Bashir's [36] strategies mentioned in section 4.1. Such efforts must address power differentials, question official cultural parochialism, open institutional doors and communicate a welcoming attitude. Civil society can make important contributions to such efforts, as exemplified by charitable organisations, neighbourhood initiatives and anonymous help lines. They, too, might benefit further from educational efforts as described above. Underlying those initiatives should be a readiness to discuss difficult issues in culturally safe environments, a readiness to listen and to engage in genuine dialogue on critical topics.

It remains to be seen how well this approach might work with such challenges as are posed by the ethnic tensions between former colonies and their former master countries around the world, and by the situation of migrant workers in many affluent societies. Historic examples, culminating in the attack on Charlie Hebdo, suggest that the absence of any preparation for offence can lead to disastrous outcomes.

\section{Limitations of the Preparatory Approach}

Possible limits of this approach are exemplified by situations where confrontation between two well-defined cultural groups has persisted in the form of protracted violent conflict for generations. A striking example is the Israel-Palestine conflict with its complex historical background; in this case preparing for offence seems pointless as both sides already live in a state of persistent and multifaceted injury, aggravated by a cultural legitimation of revenge. This and other examples show how the reasons for violent conflict can exceed the occasional cause for offence, including longstanding historical grievances, habitual abuse of entrenched power differentials, widely advocated confrontational ideologies and racism, aggravated by the poisonous influence of fundamentalist religion. Against such a background the individual experience of offence pales to insignificance, to a matter-of-fact confirmation of the perceived status quo. In a way the opposing parties are already prepared to be offended, and it offers little help.

Another obvious limit manifests in situations where the offence is too overwhelming, as in the case of over 2,ooo annual cases of female genital mutilation in the UK [44] and in other Western societies. The fact that the practice violates local law seems less offensive to the host culture than does the gross violation of universally recognised human rights, committed on cultural grounds that appear immaterial to the host but allimportant to the newcomer. This kind of moral transgression is clearly in a different category than a kosher restaurant serving pork, on account of the human suffering and injustice involved and the violation of moral norms that are globally subscribed. Asking the host culture to 'just get used to it' would merely aggravate the offence and damage the status of universal human rights. A mutually acceptable compromise seems impossible in such situations.

Motivations need to be clearly communicated by each party to prevent misunderstandings and inadvertent strain on people's patience, especially where the offence was committed deliberately. By going public, Ms Bashir went against the express wishes of her family in the conviction that the pursuit of justice and proactive safety of thousands of girls warranted the offence. She made it clear that the offensive act was deliberate, not an inadvertent slip, but that at the same time it was not her intent to offend. Such an unwavering conviction makes recurrence likely, which the other party deserves to be warned about. The chances that any preparatory efforts on their part can actually prevent conflict depend greatly on the clarity of communications, which can be aided by mediation. Communication and debate are also important in order to clarify where the perception of offence came from and to question its validity. Thus, the scope for communication also defines the room for proactive mitigation. This applies also to interactions between organisations and governments.

\section{Conclusions}

Within those limits, our examples indicate an abundance of opportunity for preventing conflict between coexisting cultures by raising the threshold at which individuals take offence, and by rendering potential offending events subject to reflection and discussion, preferably as part of anticipatory strategies. Our earlier analysis [6] identified interactive classroom strategies toward preparing to be offended. In this paper, we discussed some 
strategies to accomplish that in the public domain. We established that preparing to be offended serves to enhance cultural safety and ultimately human security.

Even in the public domain those efforts rely on education of/by government organisations and civil society, especially institutions dealing with migrants and refugees. Preparing to be offended does not necessarily mean preparing to forgive, or even merely to tolerate. Depending on the issue, it relies on efforts to communicate, to evaluate, to reason, to deliberate and to question one's own position knowing that considerations of cultural safety and justice might necessitate revising that position. At the individual level, preparing to be offended can pre-empt aggressive reactions and escalation. At the collective level, it complements and enriches approaches to conflict resolution and peace building [45].

We also saw that the need for anticipatory action is greatly increasing. Current trends suggest an unprecedented increase in intercultural encounters and occasions for taking offence, which poses a particular challenge to the sustainability of cultural safety. Especially the expected increase in refugees from inundated coastal lowlands and from regions rendered uninhabitable by changing climates will necessitate efforts in every potential host country to minimise potential friction while ensuring adequate dialogue and peaceful coexistence. Thus, the physical drivers that lend additional urgency to the project of ensuring cultural safety and put into question its sustainability are population growth and global environmental change. Aiming at cultural safety as a proactive strategy rather than at reactive management and mitigation of conflicts improves the chances of sustainable success. Nevertheless, this will not be easy for a humanity soon to exceed eight billion, living on less land, on reduced resources and in weakened economies. In the light of those global challenges exhibiting the cultural parochialism that still abounds in many communities will become much riskier. It will not be enough just to prepare to be offended. It will also not be enough to prepare not to offend. Yet those efforts constitute essential components in a recipe that might allow humanity to weather the challenges ahead in acceptable security.

\section{Acknowledgements}

An earlier version of this essay was presented at the Second International Scientific Conference on Human Security "Twenty Years of Human Security" in Belgrade, Serbia, 7-8 November 2014. The authors thank the anonymous reviewer for pertinent and constructive suggestions.

\section{References}

[1] Alkire S. Concepts of human security. In: Chen L, Fukuda-Parr S, Seidensticker E, editors. Human insecurity in a global world. Cambridge, Mass: Asia Center, Harvard University; 2003, p. 15-39.

[2] Tadjbakhsh S, Chenoy AM. Human security: concepts and implications. London: Routledge; 2007.

[3] Burgess, JP, editor. Promoting human security: ethical, normative and educational frameworks in Western Europe. Paris: UNESCO; 2007.

[4] UNHCR (United Nations High Commissioner for Refugees). War's human cost: UNHCR global trends 2013. Geneva: UNHCR; 2014.

[5] Bowers CA. Education, cultural myths, and the ecological crisis: Toward deep changes. Albany, NY: State University of New York Press; 1993.

[6] Lautensach AK, Lautensach SW. Prepare to be offended: cultural safety inside and outside the classroom. International J of Arts $\mathcal{E}$ Science 2011; 4 (25): 183-194.

[7] NAHO (National Aboriginal Health Organisation Canada). Cultural competency and safety in First Nations, Inuit, and Metis health care, 2006.

http://www.naho.ca/documents/naho/english/factSheets/culturalCom petency.pdf. Accessed 12 January 2015.
[8] NCNZ (Nursing Council of New Zealand) Code of conduct for nurses, 2011.

http://www.nursingcouncil.org.nz/Content/download/255/1172/file/Nu rses Code of Conduct.pdf Accessed 12 January 2014, p.13.

[9] Annan, K. In larger freedom: towards development, security, and human rights for all. Executive summary. New York: United Nations; 2005.

[10] Hastings D. The human security index: an update and a new release, 2011. Document Report Version 1.0

(March).http://www.humansecurityindex.org/wordpress/wpcontent/uploads/2012/02/hsiv2-documentation-report1_1.pdf Accessed 12 January 2015.

[11] Hoffstaedter G, Roche C. 2012. Security from below: an alternative perspective on human security. In Altman D, Camilleri JA, Eckersley R, Hoffstaedter G, editors. 2012. Why human security matters: rethinking Australian foreign policy. North Sydney, NSW: Allen \& Unwin; 2012, pp.148-166.

[12] Lautensach, A. Expanding human security. Australasian J of Human Security 2006; 2 (3): 5-14.

[13] UNDP (United Nations Development Programme). Human development report: new dimensions of human security. New York: UNDP; 1994.

[14] Spady D, Lautensach A. Why human security needs our attention. In Lautensach AK, Lautensach SW, editors. Human security in world affairs: problems and opportunities. Vienna, Austria: Caesarpress; 2013, p. 17-33.

[15] Lautensach AK, Lautensach SW, editors. Human security in world affairs: problems and opportunities. Introduction. Vienna, Austria: Caesarpress; 2013,

[16] Elmqvist T, Cornell S, Öhman MC, Daw T, Moberg F, Norström A, et al. Global sustainability and human prosperity: contributions to the post-2015 agenda and the development of sustainable development goals. Copenhagen: Nordic Council of Ministers; 2014.

[17] Eckersley R. Conclusion: The political virtue of human security. In Altman D, Camilleri JA, Eckersley R, Hoffstaedter G, editors. Why human security matters: rethinking Australian foreign policy. North Sydney, NSW: Allen \& Unwin; 2012, pp. 195-207.

[18] Hayes A. Individuals and groups outside of the state system. In Lautensach AK, Lautensach SW, editors. Human security in world affairs: problems and opportunities. Vienna, Austria: Caesarpress; 2013, p. 113-138.

[19] Pearce F. Search for climate refugees. New Scientist 2011 (30 April): 6-7.

[20]UNHCR (United Nations High Commissioner for Refugees). The state of the world's refugees. Geneva: UNHCR; 2006.

[21] Brislin R, Cushner K. Intercultural interactions: a practical guide. Thousand Oaks, CA: Sage Publications; 1995.

[22] Catton WR Jr. Overshoot: the ecological basis of revolutionary change. Urbana, IL: University of Illinois Press; 1980.

[23] Rees WE. Concept of ecological footprint. In Levin S, editor. Encyclopedia of Biodiversity. Salt Lake City, Utah: Academic Press/Elsevier; $2^{\text {nd }}$ ed. 2013.

[24] Wackernagel M, Schulz NB, Deumling D, Linares AC, Jenkins M, Kapos V, et al. Tracking the ecological overshoot of the human economy. Proceedings of the National Academy of Sciences (USA) 2002; 99: 9266-9271.

[25] Griggs D, Stafford-Smith M, Gaffney O, Rockström J, Öhman MC, Shyamsundar $\mathrm{P}$, et al. Sustainable development goals for people and planet. Nature 2013; 495 (21 March): 305-307.

[26] Homer-Dixon T. Environment, scarcity, and violence. Princeton, NJ: Princeton University Press; 1999.

[27] Parenti C. Tropic of chaos: climate change and the new geography of violence. New York: Nation Books; 2011.

[28] Dobkowski MN, Wallimann I. On the edge of scarcity: Environment, resources, population, sustainability and conflict. Syracuse, NY: Syracuse University Press; 2002.

[29]UNCCD (Secretariat of the UN, Convention to Combat Desertification). The convention to combat desertification, 2012. Bonn, Germany: UNCCD. http://www.unccd.int/en/Pages/default.aspx Accessed 12 January 2015.

[30]Kutter, A. The United Nations Convention to Combat Desertification policies and programs for implementation. In Land use, land cover, 
and soil sciences. Encyclopedia of Life Support Systems (EOLSS), vol.v. Paris: UNESCO; 2010. http://www.eolss.net/sample-chapters/c19/E105-06-04.pdf Accessed 12 January 2015.

[31] United Nations Department of Economic and Social Affairs (UNDESA). World migration in figures. New York: United Nations; 2013. http://www.un.org/esa/population/migration/documents/World_Migr ation_Figures_UNDESA_OECD.pdf (accessed 7 May 2015)

[32] McDonald M. Human security and the politics of security. In Altman D, Camilleri JA, Eckersley R, Hoffstaedter G, editors. Why human security matters: rethinking Australian foreign policy. North Sydney, NSW: Allen \& Unwin; 2012, p.107-126.

[33] Gimesi T. Globalizing processes. In Lautensach AK, Lautensach SW, editors. Human security in world affairs: problems and opportunities. Vienna, Austria: Caesarpress; 2013, p. 161-178.

[34] Brewer CA, McCabe M. Immigrant and refugee students in Canada. Edmonton, Alberta: Brush Education; 2014.

[35] Stemp-Morlock L. Religion is a human right. University Affairs (22 January 2014). http://www.universityaffairs.ca/opinion/in-myopinion/religion-is-a-human-right/ Accessed 12 January 2015.

[36] Bashir R. The untold story of how a culture of shame perpetuates abuse. I know, I was a victim. The Guardian (Friday 29 August 2014). http://www.theguardian.com/society/2014/aug/29/-sp-untold-storyculture-of-shame-ruzwana-bashir Accessed 12 January 2015.

[37] Perraudin F. Rotherham abuse: 'blatant' failures of care system condemned in report. The Guardian (26 August 2014). http://www.theguardian.com/society/2014/aug/26/rotherham-abusereport-blatant-failures-of-care-system-condemned Accessed 12 January 2015.

[38] Ramsden I.. Toward cultural safety. In Wepa D, editor. Cultural safety in Aotearoa New Zealand. Auckland, NZ: Pearson Education; 2005. p. 219.

[39] Baertschi B. Human dignity as a concept of a long-lasting and widespread conceptual construct. J of Bioethical Inquiry 2014; 11: 201211.

[40]Gbadegesin S. Culture and bioethics. In Kuhse H, Singer P, editors. A companion to bioethics. Oxford, UK: Wiley-Blackwell, 2nd ed. 2009; Ch.3, p. 24-35.

[41] UN (United Nations). The universal declaration of human rights. New York: United Nations; 1948.

http://www.un.org/en/documents/udhr/index.shtml Accessed 10 January 2014.

[42] Weld M. Rethinking the cult of multiculturalism. Humanist Perspectives 2013; 186 (Autumn): 20-25.

[43] Kötter T. Fostering human security through active engagement of civil society actors. Human Security Journal 2007; 4 (Summer): 44-55. http://reliefweb.int/sites/reliefweb.int/files/resources/AF102731F9oAE CCDC125741Aoo32oD36-CPHS_jun2007.pdf (accessed 7 May 2015)

[44]McVeigh T. British girls undergo horror of genital mutilation despite tough laws. The Guardian 2010 (25 July). http://www.theguardian.com/society/2010/jul/25/femalecircumcision-children-british-law Accessed 12 January 2015.

[45] Fischer D. 2013. Peacebuilding Processes. In Lautensach AK, Lautensach SW, editors. Human security in world affairs: problems and opportunities. Vienna, Austria: Caesarpress; 2013, p. 373-395. 